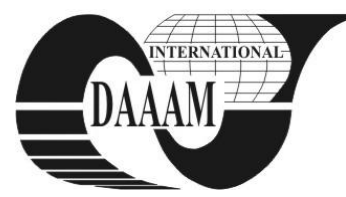

Annals of DAAAM for 2011 \& Proceedings of the 22nd International DAAAM Symposium, Volume 22, No. 1, ISSN 1726-9679 ISBN 978-3-901509-83-4, Editor B. Katalinic, Published by DAAAM International, Vienna, Austria, EU, 2011 Make Harmony between Technology and Nature, and Your Mind will Fly Free as a Bird Annals \& Proceedings of DAAAM International 2011

\title{
A NEW APPROACH TO LOWER MRP NERVOUSNESS
}

\author{
BREGNI, A[Ifredo]; D'AVINO, M[arco] \& SCHIRALDI, M[assimiliano] M.
}

\begin{abstract}
Considerable attention has been given to the MRP nervousness in case of sudden change in demand, with several solutions proposed in the last decades. This paper introduces an improved algorithm: compared to the traditional MRP, it significantly reduces the nervous behaviour, with better paced order releases and lower inventory; it also removes the need for continuous forecast adjustments.
\end{abstract}

Keywords: demand uncertainty, MRP, lot sizing, nervousness, forecasts

\section{INTRODUCTION}

The MRP (Manufacturing Requirements Planning) formula computes a future projection of the inventory level - on a time horizon at least equal to the total upstream lead-time - by algebraically summing the stock at hand, the planned receipts and the gross requirements coming from the MPS (Master Production Schedule): if the projected inventory level of a certain item gets below the predefined safety stock level, a new procurement or production order is released (Fig. 1).

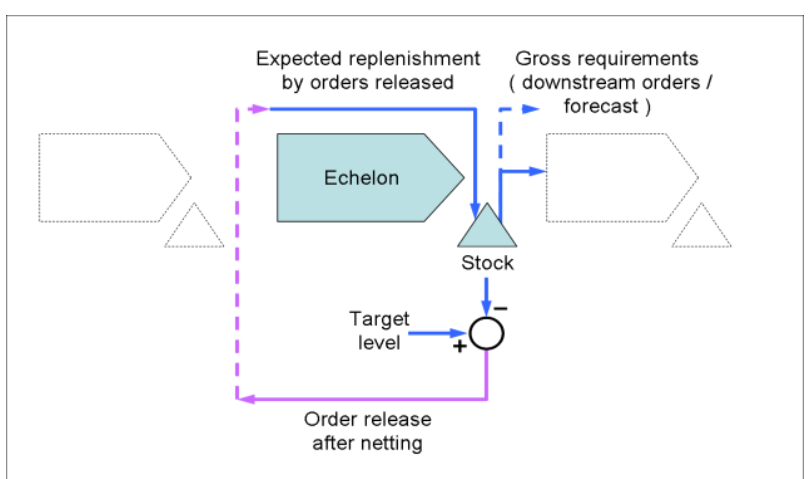

Fig. 1. Traditional MRP logic

While the MRP algorithm does work and is extensively used, it also exhibits significant drawbacks:

- Its major downside is named "nervousness", a term first coined by Daniel Steele (Steele, 1975) and analyzed in several papers (Mather, 1977), (Wemmerlov, 1979), (Vollmann et al., 1988);

- "Nervousness" entails a significant change in the MRP plans even in case of minor changes in the higher-level MRP, or MPS (notably, an issue apparently never discussed in the known literature is that nervousness is present even with stable demand, in the form of irregular order releases). In the last decades several ways have been introduced to reduce the MRP nervousness (Kadipasaoglu and Sridharan, 1995), (Inderfurth, 1994), (Blackburn et al., 1986).

One of the most significant studies is by Vollmann et al. (2005), who indicate three main guidelines to this extent:

- Introducing stability into the master schedule through devices like freezing / time fences and paying careful attention to all the parameter changes (safety stock levels, planned lead times, etc.);

- Selectively using different lot sizing techniques at different product structure levels (e.g. fixed order quantities at the top level, either fixed order quantities or lot-for-lot at intermediate levels, and period order quantities at the bottom levels);

- Introducing firm planned orders in the MRP or MPS records in order to stabilize the requirements for the lowerlevel items.

All the identified solutions to demand uncertainty and related MRP nervousness are not so effective, actually appearing as "sandbagging" (i.e. introducing safety stocks, time or capacity), introducing inflexibility to the system (i.e. fixed planned orders, freezing, etc.), or using different lot sizing techniques.

In this paper a new solution is illustrated:

- Tested in direct comparison to the traditional MRP behaviour with stable / unstable and certain / uncertain demand, it shows several advantages and lowers the overall system nervousness;

- The tests have been performed in a very simple "laboratory setting", with three echelons (end product, WIP, raw material) and a trivial Bill of Materials (1:1:1);

- The indicated setting was chosen to better highlight the behaviour of the ordering algorithm within an uncomplicated system (for the sake of simplicity, the comparisons below are performed with stable demand, a situation where improvements are already apparent).

\section{THE NEW APPROACH}

The new proposed approach improves the management of the material flow:

- The need for a short-term, demand-originated, continuously revised forecast is removed: the new computation uses the latest demand directly, which is enough to deal with, and cope for, small-OR-slow demand variations;

- Excess nervousness is eliminated, and the order release pattern made regular, by introducing a simpler and more efficient lot sizing technique.

The cause of the nervousness of the traditional algorithm is identified in production batches impacting on upstream stocks, which in turn impact on upstream order releases.

In the new computation, therefore, the very same MRP formula is adopted, but within a lot-for-lot (L4L) continuous replenishment / production algorithm (for all the echelons), with batches taken outside of the algorithmic loop and emulated L4L-related stocks (Fig. 2); to release batch orders, succeeding computations are then simply aggregated:

- Either up to a predefined batch size (for fixed batch size 
orders at variable dates);

- Or along a predefined period of time (for variable batch size orders at fixed dates).

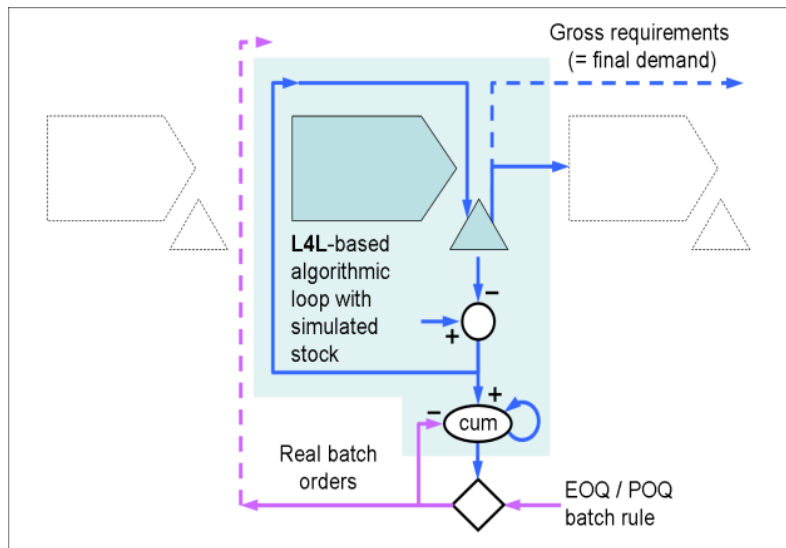

Fig. 2. New proposed logic

The proposed approach is based on the fact that:

- The Lot for Lot (L4L) technique is less affected from nervousness and high level of stocks than other lot sizing techniques (e.g. Economic Order Quantity, Period Order Quantity);

- Batch orders are released anyway, thereby overcoming the drawbacks which limit the practical application of the $\mathrm{L} 4 \mathrm{~L}$ technique, i.e. not considering certain economical aspects (e.g. high ordering costs), logistic constraints (e.g. far-off suppliers) and/or organizational issues (always changing schedule)

\section{MAIN IMPACTS AND ADVANTAGES}

Moving to the new approach allows to:

- Lower the organizational costs, by shifting the forecasting efforts away from the day-to-day demand, and focusing it on the large-AND-rapid demand variations, which need to be indicated well in advance of their occurrence;

- Smooth and stabilize the production order releases, thereby "making the shop floor life easier" (Tab. 1);

- Lower the inventory levels (Fig. 3).

\begin{tabular}{|c|c|c|c|c|c|c|c|}
\hline \multirow[b]{2}{*}{ Period } & \multirow[b]{2}{*}{ Demand } & \multicolumn{3}{|c|}{ TRADITIONAL MRP } & \multicolumn{3}{|c|}{ NEW APPROACH } \\
\hline & & $\begin{array}{c}\text { Raw } \\
\text { Material } \\
{[\mathrm{POQ}=5]}\end{array}$ & $\begin{array}{c}\text { WIP } \\
{[\mathrm{POQ}=3]}\end{array}$ & $\begin{array}{c}\text { End } \\
\text { Product } \\
{[\mathrm{POQ}=2]}\end{array}$ & \begin{tabular}{|c|} 
Raw \\
Material \\
{$[\mathrm{POQ}=5]$}
\end{tabular} & $\begin{array}{c}\text { WIP } \\
{[\mathrm{POQ}=3]}\end{array}$ & \begin{tabular}{|l}
\multicolumn{1}{c}{ End } \\
Product \\
{$[\mathrm{POQ}=2]$}
\end{tabular} \\
\hline 0 & 100 & 0 & 0 & 0 & 500 & 0 & 0 \\
\hline 1 & 100 & 0 & 0 & 200 & 0 & 0 & 200 \\
\hline 2 & 100 & 0 & 200 & 0 & 0 & 300 & 0 \\
\hline 3 & 100 & 0 & 0 & 200 & 0 & 0 & 200 \\
\hline 4 & 100 & 200 & 0 & 0 & 0 & 0 & 0 \\
\hline 5 & 100 & 0 & 400 & 200 & 500 & 300 & 200 \\
\hline 6 & 100 & 0 & 0 & 0 & 0 & 0 & 0 \\
\hline 7 & 100 & 0 & 0 & 200 & 0 & 0 & 200 \\
\hline 8 & 100 & 0 & 200 & 0 & 0 & 300 & 0 \\
\hline 9 & 100 & 600 & 0 & 200 & 0 & 0 & 200 \\
\hline 10 & 100 & 0 & 0 & 0 & 500 & 0 & 0 \\
\hline 11 & 100 & 0 & 400 & 200 & 0 & 300 & 200 \\
\hline 12 & 100 & 0 & 0 & 0 & 0 & 0 & 0 \\
\hline 13 & 100 & 0 & 0 & 200 & 0 & 0 & 200 \\
\hline 14 & 100 & 600 & 200 & 0 & 0 & 300 & 0 \\
\hline 15 & 100 & 0 & 0 & 200 & 500 & 0 & 200 \\
\hline 16 & 100 & 0 & 0 & 0 & 0 & 0 & 0 \\
\hline 17 & 100 & 0 & 400 & 200 & 0 & 300 & 200 \\
\hline 18 & 100 & 0 & 0 & 0 & 0 & 0 & 0 \\
\hline 19 & 100 & 400 & 0 & 200 & 0 & 0 & 200 \\
\hline 20 & 100 & 0 & 200 & 0 & 500 & 300 & 0 \\
\hline
\end{tabular}

Tab. 1. Better paced order releases
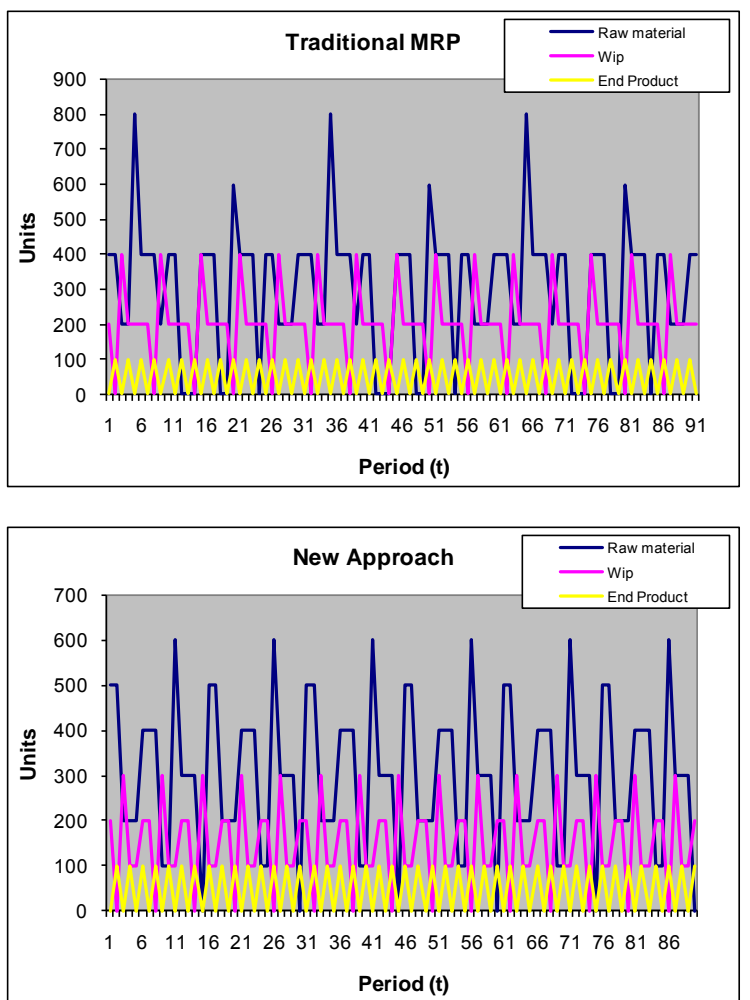

Fig. 3. Lower inventory levels

\section{CONCLUSIONS}

This paper proposes a new approach to reduce the MRP nervousness, which shows:

- No need for continuous forecast adjustments;

- A significant reduction in the nervous behaviour, with better paced order releases;

- Lower inventory.

Future research will focus on simulating the new approach in different scenarios and in real situations, deepening the simulation results (e.g. different laboratory settings, or more complicated supply chains) and developing new features (e.g. the possibility of synchronizing the activities of adjacent echelons, to further reduce the inventory levels by slashing the operating stocks).

\section{REFERENCES}

Blackburn j.d., Kropp d. h., Millen r. a. (1986). A comparison of strategies to dampen nervousness in MRP systems, Management Science, Vol. 32, No. 4

Inderfurth k. (1994). Nervousness in inventory control: analytical results, OR Spektrum 16, pp. 113-123

Kadipasaoglu s. n., Sridhran v. (1995). Alternative approaches for reducing schedule instability in multistage manufacturing under demand uncertainty, Journal of Operations Management 13, pp. 193-211

Mather h. (1977). Reschedule the schedules you just scheduled - Way of life for MRP?. Journal of Production and Inventory Management, vol. $18,1^{\text {st }}$ quarter, pag. 60-79

Vollman b., Whybark j. (1988) Manufacturing Planning and Control Systems, Down Jones Irwin, Massachusetts, pp. 333-337

Vollman b., Whybark j. (2005). Manufacturing Planning and Control for Supply Chain Management, McGraw-Hill

Wemmerlov u. (1979). Design Factors in MRP systems: a limited survey, Production and Inventory Management (Fourth quarter 1979), pp. 15-35 